\title{
Atresia Pulmonar com Comunicação Interventricular
}

\author{
Ulisses Alexandre Croti, Miguel L. Barbero, Sergio Almeida de Oliveira
}

São Paulo, SP

Estudos cineangiocardiográficos, mostrando as variações anatômicas do suprimento sangüíneo vascular pulmonar, conforme classificação de Barbero-Marcial para atresia pulmonar com comunicação interventricular.

Tipo A - Todos segmentos pulmonares supridos exclusivamente por artérias pulmonares centrais. Não existem artérias colaterais sistêmico-pulmonares (fig. 1).

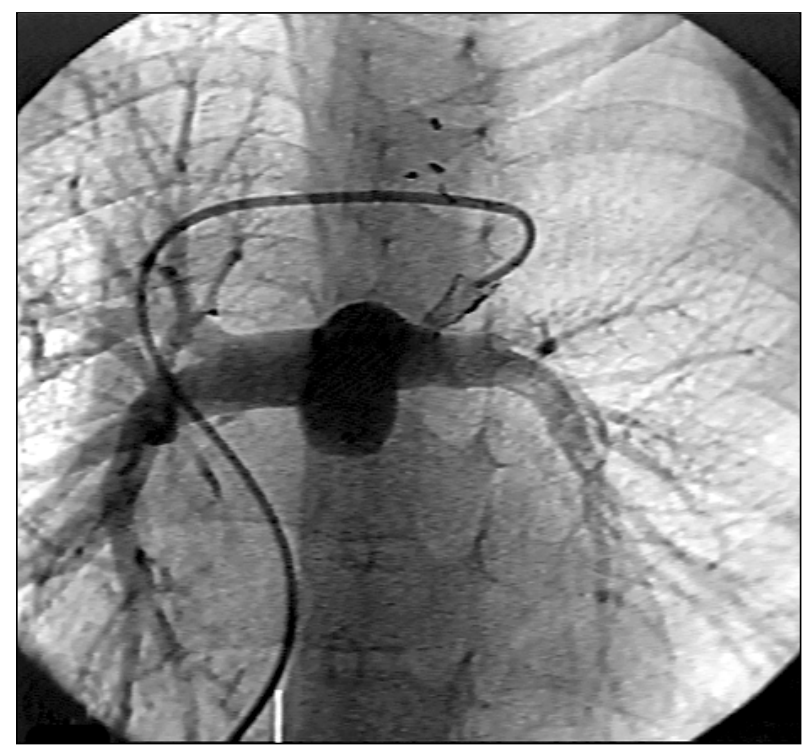

Fig. 1 - Artérias pulmonares centrais suprindo segmentos pulmonares de ambos os pulmões.
Tipo B - Segmentos pulmonares supridos por artérias pulmonares centrais e artérias colaterais sistêmico-pulmonares (figs. 2, 3 e 4 ).

Tipo C - Todos os segmentos pulmonares supridos exclusivamente por artérias colaterais sistêmico-pulmonares. Não existem artérias pulmonares centrais (figs. 5, 6, 7 e 8).

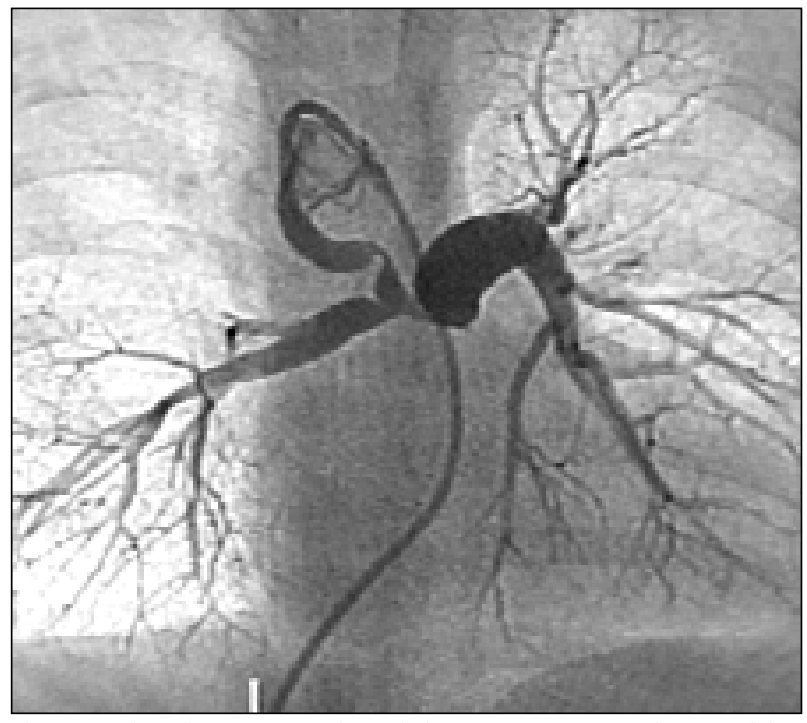

Fig. 2 - Artérias pulmonares centrais suprindo segmentos correspondentes aos lobos médio e inferior do pulmão direito e segmentos correspondentes aos lobos superior e inferior do pulmão esquerdo. 

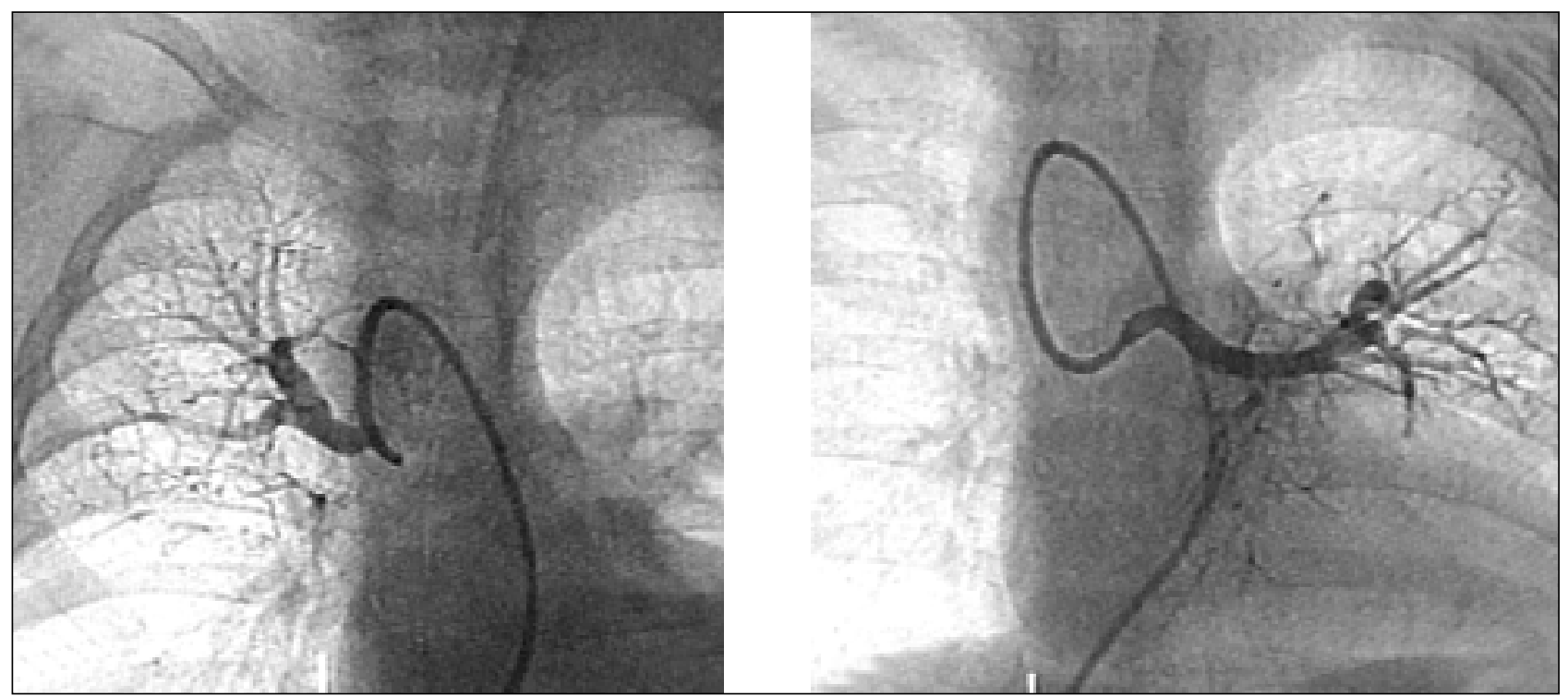

Figs. 3 e 4 - Artérias colaterais sistêmico-pulmonares, oriundas da aorta torácica descendente, suprindo segmentos correspondentes ao lobo superior do pulmão direito e segmentos correspondentes ao lobo superior e língula do pulmão esquerdo.
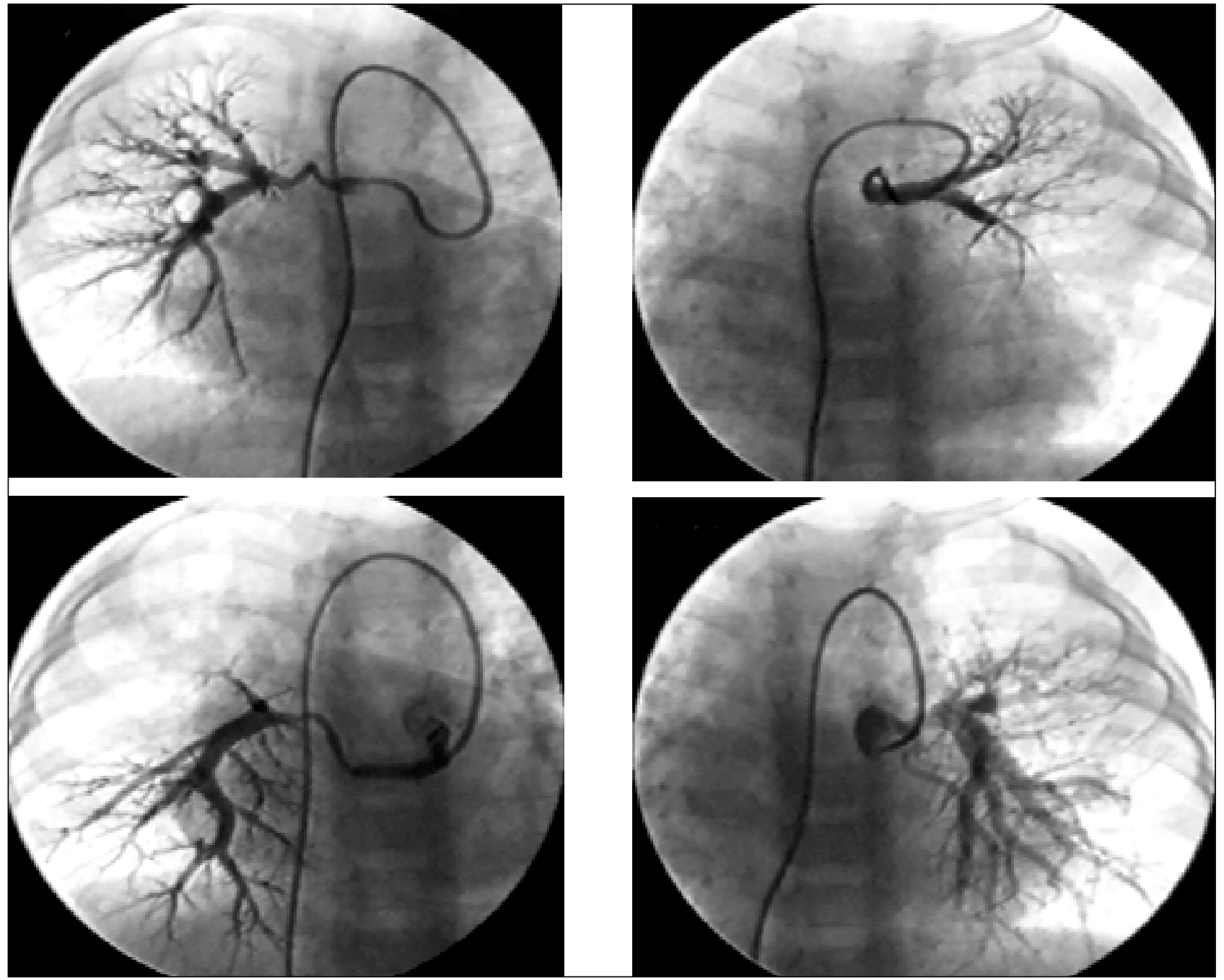

Figs. 5, 6,7 e 8 - Artérias colaterais sistêmico-pulmonares, oriundas da aorta torácica descendente, suprindo segmentos de ambos os pulmões. 


\section{Referências}

1. Barbero-Marcial ML, Jatene AD. Surgical management of the anomalies of the pulmonary arteries in the tetralogy of Fallot with pulmonary atresia. Semin Thorac Cardiovasc Surg. 1990; 1: 93-107.

2. Macé L, Dervanian P, Losay J, et al. Défauts d'arborisation pulmonaire des formes complexes d'atrésie pulmonarie à septum ouvert: unification, unifocalisation et réparation complète. Arch Mal Coeur Vaiss 1996; 89: 561-7.

3. Barbero Marcial ML. Classification of pulmonary atresia with ventricular septal defect. Ann Thorac Surg 2001; 72:316. 